\title{
Pengaruh gaya kepemimpinan, budaya sekolah dan motivasi terhadap kinerja guru SMP swasta
}

\author{
Vivi Candra ${ }^{1}$, Pasaman Silaban ${ }^{2}$, Acai Sudirman ${ }^{1 *}$ \\ ${ }^{1}$ Program Studi Manajemen, Sekolah Tinggi Ilmu Ekonomi Sultan Agung. \\ Jalan Surabaya No. 19, Pematang Siantar, Sumatera Utara 21145, Indonesia \\ ${ }^{2}$ Fakultas Ekonomi, Universitas HKBP Nommensen Medan \\ J1. Sutomo No. 4A, Medan, Sumatera Utara 20235, Indonesia \\ acaivenly@gmail.com \\ * Corresponding Author
}

\section{ARTICLE INFO}

\section{Article History}

Received:

12 June 2012;

Revised:

23 September 2019;

Accepted:

25 September 2019

\section{Keywords}

Budaya sekolah; Gaya kepemimpinan; Kinerja guru; Motivasi; School culture; Leadership style; Teacher performance; Motivation

\begin{abstract}
ABSTRAK
Tujuan dari penelitian ini untuk menguji dampak gaya kepemimpinan kepala sekolah, budaya sekolah, dan motivasi terhadap kinerja guru di SMP Swasta Sultan Agung Pematangsiantar. Jumlah anggota populasi adalah 31 orang. Oleh karena itu, penelitian ini menggunakan metode deskriptif kuantitatif dengan menggunakan kuesioner atau sensus. Instrumen penelitian dalam penelitian ini adalah kuesioner yang dibagikan secara langsung kepada responden untuk mencari data yang berhubungan dengan penelitian ini. Metode analisis data yang digunakan adalah analisis kuantitatif dan analisis kualitatif. Hasil penelitian dan hasil pengumpulan data menunjukkan bahwa secara parsial, variabel gaya kepemimpinan kepala sekolah berpengaruh signifikan terhadap kinerja guru, variabel budaya sekolah berpengaruh signifikan terhadap kinerja guru, dan variabel motivasi berpengaruh signifikan terhadap kinerja guru. Temuan empiris tersebut mengindikasikan bahwa untuk meningkatkan kinerja guru, maka SMP Swasta Sultan Agung Pematangsiantar perlu memperhatikan faktor-faktor yang mempengaruhi kinerja guru, seperti kepemimpinan kepala sekolah, budaya sekolah, dan motivasi. Dengan mengetahui pengaruh hubungan tersebut dapat dijadikan sebagai parameter untuk merancang strategi dimasa yang akan datang guna meningkatkan kinerja guru.
\end{abstract}

This study aims to examine the impact of principals' leadership style, school culture, and motivation on teacher performance at Sultan Agung Pematangsiantar Middle School. The number of members of the population is 31 people. Therefore, this study uses a quantitative descriptive method using a questionnaire or census. The research instrument in this study is a questionnaire that was distributed directly to respondents to look for data related to this study. The data analysis method used is quantitative analysis and qualitative analysis. The results of the study and the results of data collection showed that partially, the principal leadership style variable had a significant effect on teacher performance, the school culture variable had a significant effect on teacher performance, and the motivation variable had a significant effect on teacher performance. The empirical findings indicate that to improve teacher performance, Sultan Agung Pematangsiantar Middle School needs to pay attention to the factors that influence teacher performance, such as principals' leadership, school culture, and motivation. Because by knowing the effect of the relationship can be used as a parameter to design a strategy in the future to improve teacher performance.

This is an open access article under the $\mathrm{CC}-\mathrm{BY}-\mathrm{SA}$ license. 


\section{PENDAHULUAN}

Kemampuan para pendidiknya dalam mengubah karakter generasi penerus kedepannya, merupakan bagian dari interpretasi kesuksesan dunia pendidikan suatu bangsa. Bangsa besar seperti indonesia sangat membutuhkan figur pendidik, karena tanpa figur pendidik sebuah bangsa tidak akan bisa maju. Figur pendidik merupakan ujung tombak yang mendorong putra-putri Indonesia untuk terus berprestasi di tingkat nasional maupun internasional. Salah satu pencapaian putra-putri indonesia merupakan peranan penting dari seorang guru yang telah memotivasi anak muridnya untuk menjadi orang yang aktif dalam pembangunan masa depan bangsa indonesia. Kehadiran seorang guru dalam dunia pendidikan dalam membangun karakter putra-putri Indonesia dianggap penting dan harus diperhatikan secara komprehensif. Implikasi kinerja guru dalam sebuah organisasi merupakan sumber daya yang harus tetap dijaga dan ditingkatkan kemampuannya. Pada beraneka ragam aspek kehidupan khususnya kehidupan berorganisasi dalam sekolah, faktor manusia baik kepala sekolah dan guru merupakan masalah utama di setiap perspektif kegiatan yang ada didalamnya. Salah satu masalah rumit yang dihadapi bangsa ini adalah rendahnya mutu pendidikan, yang berimplikasi pada lemahnya daya saing Sumber Daya Manusia (SDM) dan rendahnya produktivitas manusia Indonesia pada umumnya. Untuk meningkatkan mutu pendidikan telah dilakukan berbagai usaha seperti peningkatan kompetensi seorang guru melalui pelatihan maupun diklat maupun perbaikan sarana prasarana pembelajaran di dalam kelas. Namun pada kenyataannya peningkatan kompetensi guru tidak cukup hanya sampai disitu saja, melainkan seorang guru butuh perhatian khusus dari kepemimpinan kepala sekolah.

Dalam dunia pendidikan perana kepala sekolah mempunyai pengaruh yang cukup besar dalam mengembangkan potensi guru dan siswanya untuk mempunyai pengetahuan secara spiritual guna pengendalian diri kepribadian, terampil dan kecerdasan. Hal ini sesuai Undang-undang Sistem Pendidikan Nasional No. 20 tahun 2003 pasal 3 bahwa pendidikan nasional berfungsi mengembangkan kemampuan potensi peserta didik agar menjadi manusia yang beriman dan bertaqwa kepada Tuhan Yang Maha Esa, berakhlaq mulia, sehat berilmu, cakap, kreatif, mandiri dan menjadi warga Negara yang demokratis serta bertanggung jawab. Untuk mewujudkan hal tersebut, dibutuhkan kinerja guru pembimbing secara optimal melalui gaya kepemimpinan kepala sekolah yang sesuai dengan keinginan seorang guru dan sesuai dengan lingkungan yang dipimpinnya. Gaya kepemimpinan merupakan kaidah atau model seorang pemimpin yang dipakai untuk mengkoordinasikan seseorang dengan cara mempengaruhi perilaku orang lain. Indikator keberhasilan seorang pemimpin dalam mengaktualisasikan kinerja yang tepat sasaran sangat bergantung pada gaya kepemimpinannya. Pemimpin yang bijaksana dan yang mengerti kondisi di sekitarnya akan menggunakan gaya kepemimpinan sesuai dengan kemampuan dan kepribadiannya dalam memimpin bawahannya. Faktor gaya kepemimpinan mempunyai pengaruh yang besar terhadap baik buruknya kinerja bawahannya yang juga menentukan baik buruknya kinerja organisasi, sebab dalam organisasi apapun bentuknya baik besar maupun kecil pasti memerlukan seorang pemimpin. Hal ini sesuai dengan yang dikemukakan Suharto (2005, p. 78) bahwa untuk mengelola dan mengendalikan berbagai fungsi subsistem dalam organisasi agar tetap konsisten dengan tujuan organisasi dibutuhkan seorang pemimpin karena pemimpin merupakan elemen yang krusial dalam pengembangan maupun peningkatan kinerja para pekerja.

Lebih lanjut Greenberg (2010, p. 195-196), menyatakan bahwa gaya kepemimpinan merupakan proses dimana seorang individu mempengaruhi cara lain untuk membantu mencapai tujuan kelompok atau organisasi. Seorang kepala sekolah memegang tanggung jawab terhadap penyelenggaraan dan pengelolaan pendidikan yang sifatnya mikro, yaitu guru sebagai pengelola utama pendidikan dalam proses pembelajaran di dalam kelas (Handayani \& Rasyid, 2015, p. 265). Menurut Al Hadromi (2017, p. 111), seorang kepala sekolah merupakan pemimpin dari sebuah organisasi, yaitu pemimpin organisasi sekolah sehingga semua aturan yang ada kaitannya dengan aktivitas sekolah merupakan aktivitas kepemimpinan dengan fungsi tertentu. Dalam dunia pendidikan, bahwa kepala sekolah memiliki peranan penting dalam mengelola satuan pendidikan sebagai manajer pendidikan. Peran pemimpinan dapat direfleksikan sebagai inisiatif dalam mempengaruhi seseorang dan bukan sifat paksaan agar setiap anggota yang ada dalam organisasi dapat termotivasi (Aguswara \& Rachmadtullah, 2017, p. 370). Keberhasilan pencapaian tujuan pendidikan dan pengajaran di sekolah merupakan manifestasi dari peranan Kepala Sekolah dalam meningkatkan kinerja guru. Seorang pemimpin dituntut untuk berperan aktif dalam mendorong integrasi yang produktif dan selaras dengan semangat kerja bawahan untuk meraih sasaran yang maksimal (Hasibuan, 2005, p. 42). Penerapan gaya kepemimpinan seorang kepala 
sekoah yang sesuai dengan sasaran akan berdampak pada kinerja guru maupun proses pengambilan keputusan yang berhubungan dengan kinerja guru (Hadi, 2015, p. 52).

Aspek lain yang dapat mempengaruhi kinerja guru adalah dinamika budaya di dalam sekolah.. Budaya sekolah menggambarkan pengaruh nilai-nilai dominan yang diimplementasikan dan dipatuhi serta dijalankan dalam suatu sekolah dengan tujuan sebagai sentral keberhasilan sekolah dalam mencapai tujuannya. Menurut Mangkunegara (2008, p. 113), budaya pada suatu organisasi tidak hanya berhubungan dengan perkiraan atau sistem kepercayaan, tetapi juga tentang nilai-nilai, dan norma yang dilestarikan pada suatu organisasi sebagai pedoman tingkah laku untuk setiap anggotanya dalam mengatasi permasalahan eksternal dan internal. Budaya sekolah memiliki kontribusi yang dominan terhadap perbaikan mutu sekolah dan mutu kehidupan yang ada di sekolah tersebut (Sidabutar, dkk, 2017, p. 39). Budaya sekolah yang memiliki karakteristik yang baik dalam suatu sekolah akan menciptakan situasi yang nyaman, sehingga akan mendorong guru bersemangat dalam bekerja untuk mencapai tujuan sekolah dengan sebaik-baiknya (Jumriatunnisah \& Tamsah, 2016, p. 26). Menurut Luthans (2006, p. 124), mengatakan budaya organisasi sebagai bentuk anggapan dasar yang diciptakan, ditemukan, atau dikembangkan pada sekelompok tertentu dengan tujuan untuk penyesuaian diri atas masalah-masalah integrasi eksternal dan integrasi internal. Budaya sekolah di SMP Swasta Sultan Agung Pematangsiantar meliputi tingkat kedisiplinan seorang guru yang harus hadir di sekolah paling lambat jam 07:15 WIB, apabila sakit harus disertai surat keterangan dokter, guru wajib memakai pakaian dinas yang sesuai dengan harinya, guru wajib melakukan piket setiap pagi secara bergiliran, dan diwajibkan untuk menghadiri kegiatan upacara bendera setiap hari Senin. Budaya sekolah yang baik akan tercipta dengan optimal jika ada bantuan dan dukungan dari kepala sekolah dan semua warga sekolah (Wibowo \& Ari, 2017, p. 182). Walaupun demikian, Budaya sekolah di SMP Swasta Sultan Agung Pematangsiantar masih kurang dalam hal sosialisasi mengenai peraturan dan tata tertib yang jelas bagi seluruh warga sekolah karena tidak dibuat secara tertulis mengenai peraturan yang harus dipatuhi oleh seluruh warga sekolah dan sanksi yang akan dikenakan jika melanggar peraturan tersebut.

Selain gaya kepemimpinan dan budaya sekolah, faktor lain yang dapat mempengaruhi kinerja guru adalah motivasi. Motivasi merupakan unsur yang dianggap krusial dalam mendukung kinerja seorang guru maupun pegawai lainnya. Guru yang bekerja dengan motivasi yang bekerja dengan motivasi yang tinggi akan menghasilkan suatu kerjaan yang sesuai dengan ekspektasi dari lingkungan organisasinya. Menurut Mulyasa (2003, p. 112), motivasi merupakan "enegri penggerak atau penarik yang menyebabkan adanya perilaku ke arah suatu tujuan tertentu". Perbedaan kinerja antara orang satu denga orang lain sebagian ditentukan oleh keinginan untuk bekerja keras dalam mencapai hasil yang optimal. Keinginan bekerja keras dipicu oleh faktor internal yang ada dalam diri orang yang disebut motivasi (Eros, 2014, p. 2). Seorang guru dapat bekerja secara professional jika pada dirinya terdapat motivasi yang tinggi. Pembaharuan serta peningkatan kinerja seorang guru melalui motivasi kerja guru merupakan elemen yang dianggap krusial untuk meningkatkan kinerja guru dalam upaya mendorong setiap guru melaksanakan tugas profesinya sesuai ketentuan yang berlaku (Ardiana, 2017, p. 16). Permasalahan yang sering dihadapin suatu organisasi dalam hal ini sekolah adalah cara memotivasi guru agar dapat memberikan dampak kepuasan atas pekerjaan yang mereka lakukan (Meindinyo \& Ikurite, 2017, p. 22). Motivasi yang diberikan kepada guru di SMP Swasta Sultan Agung Pematangsiantar berupa pemberian imbalan (gaji/honor) kepada guru dalam hitungan per jam pelajaran, memberikan dukungan dan bantuan terhadap guru untuk melanjutkan studi ke jenjang yang lebih tinggi, memberikan pakaian dinas dan tunjangan kesehatan setiap tahunnya, serta mengikutsertakan guru dalam program Jamsostek.

Kajian mengenai kinerja guru juga dijelaskan pada hasil penelitian sebelumnya menyebutkan bahwa kinerja guru dapat dipengaruhi oleh supervisi kepala sekolah, iklim sekolah, dan status ekonomi (Pramesti \& Muhyadi, 2018, p. 55). Selanjutnya hasil penelitian Pramudyo (2010, p. 9), menyatakan selain motivasi dan kepemimpinan, faktor kompetensi dan lingkungan kerja juga mempengaruhi kinerja dosen. Sehubungan dengan uraian di atas dan adanya gap antara teori sebelumnya serta penelitian sebelumnya, maka penulis tertarik untuk mengkaji lebih jauh mengenai faktor-faktor yang mempengaruhi kinerja guru perlu dibuktikan dengan mengadakan penelitian dengan judul "Analisis Pengaruh Gaya Kepemimpinan, Budaya Sekolah, dan Motivasi Terhadap Kinerja Guru pada SMP Swasta Sultan Agung Pematangsiantar". Adapun tujuan penelitian ini adalah untuk menganalisis besarnya pengaruh gaya kepemimpinan, budaya sekolah dan motivasi terhadap kinerja guru. Penelitian ini dilaksanakan di SMP Swasta Sultan Agung Pematangsiantar. 


\section{METODE}

Metode yang digunakan dalam penelitian ini adalah metode survey dengan pendekatan kuantitatif. Studi dalam penelitian ini untuk mengetahui pengaruh antara variabel bebas yakni gaya kepemimpinan, budaya sekolah dan motivasi terhadap variabel terikat, yaitu kinerja guru. Populasi dalam penelitian ini adalah seluruh guru SMP Swasta Sultan Agung Jalan Surabaya No.19, Kelurahan Dwikora, Kecamatan Siantar Barat, Kota Pematangsiantar yang berjumlah sebanyak 31 orang. Pengambilan sampel dilakukan dengan metode sensus, dimana jumlah keseluruhan populasi dijadikan sampel. Data dikumpulkan dengan menggunakan penyebaran kuesioner. Penelitian ini menggunakan kuesioner dalam bentuk formulir atau lembaran isian yang berisi pertanyaan dari masing-masing indikator variabel penelitian, yakni pertanyaan untuk indikator gaya kepemimpinan, budaya sekolah dan motivasi serta kinerja guru. Sebelum kuesioner dijalankan kepada responden, maka terlebih dahulu dilakukan uji validitas dan reliabilitas untuk menguji kelayakan model pertanyaan masing-masing variabel. Kriteria untuk data yang dikategorikan valid menggunakan rumus pearson product moment dan untuk uji reliabilitas dilakukan dengan memakai rumus cronbach's alpha if item deleted. Uji hipotesis pada penelitian ini menggunakan uji parsial (uji t) dan uji simultan (uji f) yang diperoleh dari hasil regresi linier berganda. Sebelum melakukan regresi linier terlebih dahulu diuji asumsi klasiknya, yakni uji normalitas, uji heteroskedastisitas dan multikolinearitas. Untuk persamaan regresi berganda adalah $\hat{\mathrm{Y}}=\mathrm{a}+\mathrm{b}_{1} \mathrm{x}_{1}+\mathrm{b}_{2} \mathrm{x}_{2}+\mathrm{b}_{3} \mathrm{x}_{3}$. Pengambilan keputusan dengan ketentuan signifikan $>0,05$ dan $\mathrm{t}_{\text {hitung }}<$ $t_{\text {tabel, }}$, maka Ho diterima (Ha ditolak), sedangkan signifikansi $\leq 0,05$ dan $t_{\text {hitung }}>t_{\text {tabel }}$, maka Ho ditolak (Ha diterima).

\section{HASIL DAN PEMBAHASAN}

Deskripsi Hasil Penelitian

Sesuai dengan hasil data penelitian yang dilakukan dari pembagian serta pengisian angket, maka diperoleh data tentang umur responden yang dapat dilihat pada Tabel 1. Data Tabel 1 menunjukan bahwa guru-guru SMP Swasta Sultan Agung Pematangsiantar memiliki usia yang bervariasi. Usia guruguru SMP Swasta Sultan Agung kebanyakan diatas 40 tahun. Secara fisik dan psikologis faktor usia adalah indikator yang dinilai memiliki pengaruh terhadap cara bekerja seseorang. Sesuai dengan data kuesioner yang diperoleh dari penyebaran angket, maka diperoleh data tentang umur responden yang dapat dilihat pada Tabel 1. Data Tabel 1 menunjukan bahwa guru-guru SMP Swasta Sultan Agung Pematangsiantar memiliki usia yang bervariasi. Usia guru-guru SMP Swasta Sultan Agung kebanyakan diatas 40 tahun. Secara fisik dan psikologis faktor usia merupakan salah satu faktor yang mempengaruhi cara bekerja seseorang. Seseorang yang memiliki usia diantara 25 sampai 50 dianggap memiliki kinerja yang produktif dalam melakukan pengajaran di dalam kelas.

Tabel 1. Responden Berdasarkan Usia

\begin{tabular}{ccc}
\hline $21-30$ tahun & 2 & 6,45 \\
$31-40$ tahun & 12 & 38,7 \\
$41-50$ tahun & 10 & 32,1 \\
$>50$ tahun & 7 & 22,4 \\
Jumlah & 31 & 100 \\
\hline
\end{tabular}

Sumber : Data Primer diolah 2018

Responden Berdasarkan Jenis Kelamin

Secara fisik dan psikologis faktor jenis kelamin juga merupakan salah satu faktor yang mempengaruhi perilaku seseorang dalam melaksanakan pekerjaannya. Data Tabel 2 menunjukkan bahwa mayoritas SMP Swasta Sultan Agung memiliki jumlah guru perempuan yang lebih banyak $(54,83 \%)$ dibandingkan dengan laki-laki $(45,17 \%)$. Hal ini disebabkan tenaga guru yang berjenis kelamin perempuan memiliki intuisi yang lebih kuat untuk memahami keinginan murid terutama murid yang berjenis kelamin wanita. Peranan guru yang berjenis kelamin pria cenderung memetingkan hasil 
akhir ketimbang proses dalam pembelajaran untuk memperoleh hasil belajar. Jumlah responden berdasarkan jenis kelamin dapat dilihat pada Tabel 2.

Tabel 2. Responden Berdasarkan Jenis Kelamin

\begin{tabular}{ccc}
\hline Jenis Kelamin & Jumlah & Persentase \\
\hline Pria & 14 & 45,17 \\
Wanita & 17 & 54,83 \\
Jumlah & 31 & 100 \\
\hline
\end{tabular}

Sumber : Data Primer diolah 2018

Responden berdasarkan Tingkat Pendidikan Terakhir

Jumlah responden berdasarkan pendidikan terakhir di lingkungan SMP Swasta Sultan Agung Pematangsiantar dapat dilihat dari Tabel 3. Data Tabel 3 menunjukan bahwa mayoritas pendidikan terakhir Guru SMP Swasta Sultan Agung Pematangsiantar adalah Sarjana S-1 sebanyak 21 orang atau $67,7 \%$ disusul dengan tingkat pendidikan Pascasarjana ( S-2) sebanyak 7 orang atau 22,6\% kemudian tingkat Diploma 2 Orang atau 6,45\% dan yang terakhir SMA 1 orang atau 3,23\%. Kondisi tersebut menggambarkan bahwa, tingkat pendidikan seorang memiliki kontribusi yang signifikan terhadap proses pembelajaran di kelas. Semakin tinggi tingkat pendidikan seseorang, maka semakin mempermudah organisasi sekolah dalam mengembangkan bakat serta kemampuan mengajarnya.

Tabel 3. Reponden Berdasarkan Tingkat Pendidikan Terakhir

\begin{tabular}{ccc}
\hline Tingkat Pendidikan & Jumlah & Persentase \\
\hline SMA & 1 & 3,24 \\
Diploma & 2 & 6,46 \\
Sarjana ( S1 ) & 21 & 67,7 \\
Pasca Sarjana ( S2) & 7 & 22,6 \\
Jumlah & 31 & 100 \\
\hline
\end{tabular}

Sumber : Data Primer, diolah 2018

Responden Berdasarkan Status Kepegawaian

Jumlah responden berdasarkan status kepegawaian dapat dilihat dari Tabel 4. Data Tabel 4 menunjukkan bahwa guru tetap adalah yang paling banyak jumlahnya dengan 12 orang guru tetap atau $38,7 \%$ dan diikuti guru tidak tetap yayasan dengan jumlah 19 orang guru atau $61,3 \%$. Kondisi ini merefleksikan bahwa guru tetap yang ada di lingkungan sekolah masih minim jumlahnya sehingga kedepannya perlu dilakukan perekrutan guru tetap untuk meningkatkan status kepegawaian guru tetap di lingkungan Sekolah Menengah Pertama (SMP) Sultan Agung Pematangsiantar.

Tabel 4. Reponden Berdasarkan Status Kepegawaian

\begin{tabular}{ccc}
\hline Status Kepegawaian & Jumlah & Persentase \\
\hline Guru Tetap & 12 & 38,7 \\
Guru Tidak Tetap & 19 & 61,3 \\
Jumlah & 31 & 100 \\
\hline
\end{tabular}

Sumber: Data Primer diolah, 2018

Uji Validitas

Pengujian validitas menggunakan software statistic (SPSS), nilai validitas ditunjukkan pada kolom Corrected Item Total Correlation. Jika angka korelasi yang diperoleh lebih besar dari pada angka kritik ( $r$-hitung $>r$-tabel) maka instrument tersebut dikatakan valid. Berdasarkan uji validitas dapat disimpulkan bahwa seluruh item pertanyaan untuk mengukur masing-masing variable penelitian 
dinyatakan valid. Hal ini dapat dilihat bahwa r-hitung lebih besar dari r-table maka dengan derajad bebas atau df 30 (33-3) berarti r-tabel $(0,05 ; 30)$ adalah 0,349 dapat digambarkan pada Tabel 5.

Tabel 5. Uji Validitas

\begin{tabular}{|c|c|c|c|c|}
\hline Variabel & Butir Instrumen & r hitung & $\mathrm{r}$ tabel & Keterangan \\
\hline \multirow{10}{*}{$\begin{array}{c}\text { Gaya } \\
\text { Kepemimpinan }\end{array}$} & XI.1 & 0,565 & 0.3 & Valid \\
\hline & $\mathrm{X} 1.2$ & 0.565 & 0.3 & Valid \\
\hline & $\mathrm{X} 1.3$ & 0.502 & 0.3 & Valid \\
\hline & $\mathrm{X} 1.4$ & 0.573 & 0.3 & Valid \\
\hline & $\mathrm{X} 1.5$ & 0.638 & 0.3 & Valid \\
\hline & $\mathrm{X} 1.6$ & 0.502 & 0.3 & Valid \\
\hline & $\mathrm{X} 1.7$ & 0.573 & 0.3 & Valid \\
\hline & $\mathrm{X} 1.8$ & 0.502 & 0.3 & Valid \\
\hline & X1.9 & 0.573 & 0.3 & Valid \\
\hline & $\mathrm{X} 1.10$ & 0.608 & 0.3 & Valid \\
\hline \multirow{10}{*}{$\begin{array}{c}\text { Budaya } \\
\text { Organisasi }\end{array}$} & $\mathrm{X} 2.1$ & 0.499 & 0.3 & Valid \\
\hline & $\mathrm{X} 2.2$ & 0.587 & 0.3 & Valid \\
\hline & $\mathrm{X} 2.3$ & 0.669 & 0.3 & Valid \\
\hline & $\mathrm{X} 2.4$ & 0.365 & 0.3 & Valid \\
\hline & $\mathrm{X} 2.5$ & 0.512 & 0.3 & Valid \\
\hline & $\mathrm{X} 2.6$ & 0.587 & 0.3 & Valid \\
\hline & $\mathrm{X} 2.7$ & 0.647 & 0.3 & Valid \\
\hline & $\mathrm{X} 2.8$ & 0.536 & 0.3 & Valid \\
\hline & X2.9 & 0.573 & 0.3 & Valid \\
\hline & $\mathrm{X} 2.10$ & 0.646 & 0.3 & Valid \\
\hline \multirow{10}{*}{ Motivasi Guru } & X 3.1 & 0.624 & 0.3 & Valid \\
\hline & X3.2 & 0.471 & 0.3 & Valid \\
\hline & X3.3 & 0.674 & 0.3 & Valid \\
\hline & X 3.4 & 0.615 & 0.3 & Valid \\
\hline & X3.5 & 0.502 & 0.3 & Valid \\
\hline & X3.6 & 0.612 & 0.3 & Valid \\
\hline & X3.7 & 0.555 & 0.3 & Valid \\
\hline & X3.8 & 0.438 & 0.3 & Valid \\
\hline & X3.9 & 0.485 & 0.3 & Valid \\
\hline & X3.10 & 0.621 & 0.3 & Valid \\
\hline \multirow{10}{*}{$\begin{array}{l}\text { Kinerja } \\
\text { Guru }\end{array}$} & $\mathrm{Y} 1$ & 0.485 & 0.3 & Valid \\
\hline & Y2 & 0.720 & 0.3 & Valid \\
\hline & Y3 & 0.495 & 0.3 & Valid \\
\hline & Y4 & 0.553 & 0.3 & Valid \\
\hline & Y5 & 0.694 & 0.3 & Valid \\
\hline & Y6 & 0.687 & 0.3 & Valid \\
\hline & Y7 & 0.471 & 0.3 & Valid \\
\hline & Y8 & 0.377 & 0.3 & Valid \\
\hline & Y9 & 0.037 & 0.3 & Valid \\
\hline & Y10 & 0.504 & 0.3 & Valid \\
\hline
\end{tabular}

Sumber: Data Primer diolah 2018, SPSS 21

Data tabel di atas menunjukkan bahwa item pertanyaan variabel-variabel penelitian mempunyai nilai korelasi $\left(\mathrm{r}_{\text {hitung }}\right.$ ) yang lebih besar dari $\mathrm{r}_{\text {tabel }}$, yaitu 0,30 item pertanyaan variabel-variabel penelitian semua valid dan dapat digunakan dalam analisis selanjutnya. 
Uji Reliabilitas

Uji reliabilitas dilakukan untuk memperlihatkan objektivitas dan konsistensi suatu pertanyaan dalam bentuk alat ukur dapat dipercaya. Menurut Ghozali, suatu variabel layak dinyatakan reliabel jika memberikan nilai cronbach's alpha $>0,70$. Jawaban kuesioner penelitian tersebut dinyatakan reliabel karena masing-masing pertanyaan dijawab secara konsisten. Suatu konstruk atau butir instrumen dinyatakan reliabel jika memberikan nilai cronbach alpha $>0,70$. Berdasarkan hasil pengujian data menunjukkan bahwa nilai cronbach`s alpha dari masing-masing variabel yang diteliti $>0,70$. Hal ini menunjukkan bahwa instrument tersebut reliable seperti yang disajikan pada Tabel 6 .

Tabel 6. Uji Reliabilitas

\begin{tabular}{|c|c|c|c|c|}
\hline Variabel & Butir Instrumen & $\begin{array}{c}\text { Cronbach's Alpha if } \\
\text { Item Deleted }\end{array}$ & $\begin{array}{c}\text { Cronbach's } \\
\text { Alpha }\end{array}$ & Keterangan \\
\hline \multirow{9}{*}{$\begin{array}{c}\text { Gaya } \\
\text { Kepemimpinan }\end{array}$} & XI.1 & .816 & 0.7 & Reliabel \\
\hline & $\mathrm{X} 1.2$ & .811 & 0.7 & Reliabel \\
\hline & $\mathrm{X} 1.3$ & .806 & 0.7 & Reliabel \\
\hline & $\mathrm{X} 1.4$ & .793 & 0.7 & Reliabel \\
\hline & $\mathrm{X} 1.5$ & .811 & 0.7 & Reliabel \\
\hline & $\mathrm{X} 1.6$ & .806 & 0.7 & Reliabel \\
\hline & $\mathrm{X} 1.7$ & .793 & 0.7 & Reliabel \\
\hline & $\mathrm{X} 1.8$ & .806 & 0.7 & Reliabel \\
\hline & $\mathrm{X} 1.9$ & .793 & 0.7 & Reliabel \\
\hline \multirow{11}{*}{$\begin{array}{l}\text { Budaya } \\
\text { Organisasi }\end{array}$} & $\mathrm{X} 1.10$ & .811 & 0.7 & Reliabel \\
\hline & $\mathrm{X} 2.1$ & .767 & 0.7 & Reliabel \\
\hline & $\mathrm{X} 2.2$ & .774 & 0.7 & Reliabel \\
\hline & $\mathrm{X} 2.3$ & .767 & 0.7 & Reliabel \\
\hline & $\mathrm{X} 2.4$ & .801 & 0.7 & Reliabel \\
\hline & $\mathrm{X} 2.5$ & .782 & 0.7 & Reliabel \\
\hline & $\mathrm{X} 2.6$ & .774 & 0.7 & Reliabel \\
\hline & $\mathrm{X} 2.7$ & .772 & 0.7 & Reliabel \\
\hline & $\mathrm{X} 2.8$ & .772 & 0.7 & Reliabel \\
\hline & X2.9 & .774 & 0.7 & Reliabel \\
\hline & $\mathrm{X} 2.10$ & .759 & 0.7 & Reliabel \\
\hline \multirow{9}{*}{ Motivasi } & X3.1 & .784 & 0.7 & Reliabel \\
\hline & $\mathrm{X} 3.2$ & .810 & 0.7 & Reliabel \\
\hline & $\mathrm{X} 3.3$ & .792 & 0.7 & Reliabel \\
\hline & X3.4 & .805 & 0.7 & Reliabel \\
\hline & $\mathrm{X} 3.5$ & .809 & 0.7 & Reliabel \\
\hline & X3.6 & .784 & 0.7 & Reliabel \\
\hline & $\mathrm{X} 3.7$ & .792 & 0.7 & Reliabel \\
\hline & $\mathrm{X} 3.8$ & .820 & 0.7 & Reliabel \\
\hline & X3.9 & .811 & 0.7 & Reliabel \\
\hline \multirow{11}{*}{$\begin{array}{c}\text { Kinerja } \\
\text { Guru }\end{array}$} & $\mathrm{X} 3.10$ & .790 & 0.7 & Reliabel \\
\hline & Y1 & .730 & 0.7 & Reliabel \\
\hline & Y2 & .703 & 0.7 & Reliabel \\
\hline & Y3 & .739 & 0.7 & Reliabel \\
\hline & Y4 & .748 & 0.7 & Reliabel \\
\hline & Y5 & .715 & 0.7 & Reliabel \\
\hline & Y6 & .716 & 0.7 & Reliabel \\
\hline & Y7 & .759 & 0.7 & Reliabel \\
\hline & Y8 & .741 & 0.7 & Reliabel \\
\hline & Y9 & .745 & 0.7 & Reliabel \\
\hline & Y10 & .755 & 0.7 & Reliabel \\
\hline
\end{tabular}

Sumber : Data Primer diolah 2018 ,SPSS 21 
Uji Normalitas

Uji normalitas dapat digunakan uji one-sample Kolmogrov- Smirnov dengan menggunakan program pengolahan data yakni SPSS versi 21. Pedoman yang digunakan sebagai landasan dalam pengambilan keputusan dalam uji normalitas, yakni jika nilai Asymp.sig (2-tailed) lebih besar dari 0,05 maka data tersebut berdistribusi normal. Melihat hasil uji normalitas dapat digunakan uji OneSample Kolmogrov- Smirnov. Pada tabel 7 dapat dlihat nilai yang diperoleh untuk gaya kepemimpinan sebesar 0.560 , budaya sekolah sebesar 0.845 , motivasi sebesar 0.228 dan kinerja guru sebesar 0.351 , maka dapat disimpulkan bahwa seluruh variabel dalam penelitian ini berdistribusi secara normal.

Tabel 7. Uji Normalitas One-Sample Kolmogorov-Smirnov Test

\begin{tabular}{|c|c|c|c|c|c|}
\hline & & Gaya Kepemimpinan & Budaya Sekolah & Motivasi & Kinerja Guru \\
\hline $\mathrm{N}$ & & 31 & 31 & 31 & 31 \\
\hline \multirow[t]{2}{*}{ Normal Parameters ${ }^{\mathrm{a}, \mathrm{b}}$} & Mean & 35.35 & 36.61 & 32.90 & 37.77 \\
\hline & Std. Deviation & 5.017 & 4.897 & 4.664 & 4.161 \\
\hline \multirow[t]{3}{*}{ Most Extreme Differences } & Absolute & .145 & .110 & .198 & .167 \\
\hline & Positive & .145 & .098 & .189 & .167 \\
\hline & Negative & -.126 & -.110 & -.198 & -.093 \\
\hline Kolmogorov-Smirnov Z & & .791 & .614 & 1.041 & .932 \\
\hline Asymp. Sig. (2-tailed) & & .560 & .845 & .228 & .351 \\
\hline
\end{tabular}

Sumber : Data Primer diolah 2018 ,SPSS 21

Uji Multikolinieritas

Multikolinearitas adalah keadaan yang menggambarkan hubungan yang linier atau korelasi yang tinggi diantara variabel independen dalam model regresi. Pada umumnya multikolinearitasi dapat terjadi ketika sebagian besar variabel yang digunakan saling terkait dalam suatu model regresi. Berdasarkan pengujian multikolinearitas yang dilakukan dengan melihat nilai VIF (Variance Inflation Factor), maka dapat disimpulkan bahwa tidak terjadi multikolinearitas karena tidak ada nilai VIF yang lebih besar dari 10 dan nilai Tolerance tidak kurang dari 0,1. Ringkasan pengujian multikolinearitas dapat dilihat pada Tabel 8.

Tabel 8 Uji Multikolinieritas Coefficients ${ }^{a}$

\begin{tabular}{|c|c|c|c|c|c|c|c|}
\hline \multirow[t]{2}{*}{ Model } & \multicolumn{2}{|c|}{$\begin{array}{c}\text { Unstandardized } \\
\text { Coefficients }\end{array}$} & \multirow{2}{*}{$\begin{array}{c}\text { Standardized } \\
\text { Coefficients } \\
\text { Beta }\end{array}$} & \multirow[t]{2}{*}{$T$} & \multirow[t]{2}{*}{ Sig. } & \multicolumn{2}{|c|}{ Collinearity Statistics } \\
\hline & $\mathrm{B}$ & Std. Error & & & & Tolerance & $V I F$ \\
\hline (Constant) & 7,480 & 2,635 & & 2,820 & 0,009 & & \\
\hline Gaya Kepemimpinan & 0,354 & 0,098 & 0,427 & 3,599 & 0,001 & 0,443 & 2,258 \\
\hline Budaya Organisasi & 0,269 & 0,110 & 0,317 & 2,447 & 0,021 & 0,371 & 2,693 \\
\hline Motivasi & 0,241 & 0,112 & 0,270 & 2,154 &, 040 & 0,397 & 2,518 \\
\hline a. Dependent Variable: Kin & a Guru & & & & & & \\
\hline
\end{tabular}

Sumber : Data Primer diolah 2018 ,SPSS 21 
Analisis Regresi Linier Berganda

Teknik analisa data yang digunakan dalam penelitian ini adalah analisa statistik regresi linier berganda dengan menggunakan program SPSS 21. Analisis regresi digunakan untuk memprediksi pengaruh variabel bebas terhadap variabel terikat. Teknik analisa statistik regresi linear berganda dengan menggunakan program SPSS 21. Hasil analisa regresi berganda digunakan untuk melihat pengaruh dari variabel independet/bebas terhadap variabel dependent/terikat dapat dilihat pada Tabel 9 berikut ini: $\mathbf{Y}=\mathbf{7 , 4 8 0}+\mathbf{0 , 3 5 4} \mathbf{X}_{\mathbf{1}}+\mathbf{0 , 2 6 9} \mathbf{X}_{\mathbf{2}}+\mathbf{0 , 2 4 1} \mathbf{X}_{\mathbf{3}}$ Nilai konstanta sebesar 7,480 menunjukkan bahwa apabila variabel Gaya Kepemimpinan, Budaya Sekolah, dan Motivasi diasumsikan bernilai nol, maka nilai dari Kinerja Guru adalah sebesar 7,480. Gaya Kepemimpinan berpengaruh positif terhadap Kinerja Guru SMP Swasta Sultan Agung Pematangsiantar dengan nilai koefisien $b_{1}$ sebesar 0,354 artinya jika setiap terjadi pertambahan $1 \%$ Gaya Kepemimpinan, maka akan menambah Kinerja Guru sebesar $0,354 \%$. Budaya Sekolah berpengaruh positif terhadap Kinerja Guru SMP Swasta Sultan Agung Pematangsiantar dengan nilai koefisien $b_{2}$ sebesar 0,269 artinya jika setiap terjadi pertambahan 1\% Budaya Sekolah, maka akan menambah Kinerja Guru sebesar 0,269\%. Motivasi berpengaruh positif terhadap Kinerja Guru SMP Swasta Sultan Agung Pematangsiantar dengan nilai koefisien $b_{3}$ sebesar 0,241 artinya jika setiap terjadi pertambahan $1 \%$ Motivasi, maka akan menambah Kinerja Guru sebesar 0,241\%.

Kondisi ini mengartikan bahwa ketiga variabel bebas yakni Gaya Kepemimpinan, Budaya Sekolah dan Motivasi menunjukkan pengaruh yang searah atau positif terhadap Kinerja Guru, di mana jika setiap terjadi kenaikan pada Gaya Kepemimpinan Kepala Sekolah, Budaya Sekolah, dan Motivasi, maka akan menyebabkan Kinerja Guru meningkat, dan sebaliknya jika setiap terjadi penurunan pada Gaya Kepemimpinan Kepala Sekolah, Budaya Sekolah, dan Motivasi, maka akan menyebabkan Kinerja Guru menurun. Oleh karena itu, dapat disimpulkan terdapat hubungan yang searah dan positif antara variabel bebas dengan variabel terikatnya dan untuk variabel gaya kepemimpinan memiliki pengaruh yang dominan terhadap perubahan serta peningkatan kinerja guru.

Koefisien Determinasi

Tabel 9. Koefisien Determinasi Model Summary

\begin{tabular}{ccccc}
\hline Model & $\mathrm{R}$ & R Square & Adjusted R Square & Srd. Error of the Estimate \\
\hline 1 & 0.912 & 0.832 & 0.813 & 1.799 \\
\hline
\end{tabular}

Sumber : Data Primer diolah 2018,SPSS 21

Berdasarkan Tabel 9 diperoleh nilai korelasi sebesar 0,912 yang artinya terdapat hubungan yang sangat kuat antara variabel independen yang terdiri dari Gaya Kepemimpinan, Budaya Sekolah, Motivasi dan variabel dependent yaitu kinerja. Sedangkan nilai koefisien determinasi diperoleh sebesar 0,813 atau $81,3 \%$ yang artinya kinerja guru dipengaruhi oleh gaya kepemimpinan, Budaya Sekolah, Motivasi sebesar $81,3 \%$ sedangkan sisanya $18,6 \%$ dijelaskan oleh variabel lain yang tidak diteliti.

Uji Hipotesis

\section{Uji Signifikansi Parsial (Uji t)}

Uji $t$ pada dasarnya menunjukkan seberapa jauh pengaruh variabel bebas secara individual dalam menerangkan variasi variabel terikat. Berdasarkan hasil pengolahan data sesuai Tabel 8 , maka diperoleh hasil uji parsial yaitu: Hasil pengujian variabel gaya kepemimpinan diperoleh $\mathrm{t}_{\text {hitung }} 3,599$ dengan probabilitas signifikan 0,001 lebih kecil dari tingkat keyakinan (level of significant) $\alpha=$ 0,05 , maka keputusan yang diambil adalah menolak Ho dan menerima Ha. Artinya secara parsial gaya kepemimpinan berpengaruh positif dan signifikan terhadap kinerja guru SMP Sultan Agung Pematangsiantar. Hasil pengujian variabel budaya organisasi diperoleh $t_{\text {hitung }} 2,447$ dengan probabilitas signifikan 0,021 lebih kecil dari tingkat keyakinan (level of significant) $\alpha=0,05$, maka keputusan yang diambil adalah menolak Ho dan menerima Ha, artinya secara parsial budaya organisasi berpengaruh positif dan signifikan terhadap kinerja guru SMP Swasta Sultan Agung 
Pematangsiantar. Selanjutnya hasil pengujian variabel Motivasi diperoleh $t_{\text {hitung }} 2,154$ dengan probabilitas signifikan 0,040 lebih kecil dari tingkat keyakinan (level of significant) $\alpha=0,05$. Maka keputusan yang diambil adalah menolak Ho dan menerima Ha, artinya secara parsial motivasi berpengaruh positif dan signifikan terhadap.

Uji F Statistik (Uji Simultan)

Pengujian hipotesa satu dilakukan dengan menggunakan alat uji statistik yaitu Uji F. Uji F dilakukan untuk mengetahui pengaruh variabel bebas secara simultan atau serempak terhadap variabel terikat. Untuk menguji hasil perhitungan regresi dapat dilakukan pembuktian hipotesa untuk mengetahui apakah variabel bebas mempunyai pengaruh yang signifikan atau tidak terhadap variabel terikat secara simultan. Hasil uji F pada penelitian ini dapat dilihat pada tabel berikut ini:

Tabel 10. Uji F Statistik Anova

\begin{tabular}{llccccc}
\hline \multicolumn{1}{r}{ Model } & Sum of Squares & df & Mean Square & F & Sig. \\
\hline \multirow{3}{*}{1} & Regression & 432.053 & 3 & 144.018 & 44.508 & $.000^{\mathrm{b}}$ \\
Residual & 87.366 & 28 & 3.236 & & \\
& Total & 519.419 & 31 & & & \\
\hline
\end{tabular}

a. Predictors: (Constant): Gaya Kepemimpinan, Budaya Sekolah, Motivasi

b. Dependent Variable: Kinerja Guru

Sumber : Data Primer diolah 2018 ,SPSS 21

Berdasarkan Tabel 10 diperoleh nilai $\mathrm{F}_{\text {hitung }}$ dengan dk = n-k-1 (44-2-1=41) sebesar 44,508 $>\mathrm{F}_{\text {tabel }}$ dengan $(0,05 ; 2$ vs 28$)$ sebesar 3,34 atau dengan signifikan $0,000<\alpha 0,05$, maka $\mathrm{H}_{0}$ ditolak, artinya gaya kepemimpinan, budaya sekolah dan motivasi berpengaruh positif dan signifikan terhadap kinerja guru pada SMP Swasta Sultan Agung Pematangsiantar. Dengan demikian, hasil ini sejalan dengan penelitian sebelumnya yang dilakukan oleh Handayani dan Rasyid (2015, p. 274) dan Adinata $(2015$, p. 153). Hal ini mengindikasikan bahwa hubungan antara variabel kepemimpinan, budaya organisasi, dan motivasi memiliki keterkaitan yang sangat dominan dalam mempengaruhi hasil.

\section{SIMPULAN}

Berdasarkan hasil penelitian dan analisis data mengenai gaya kepemimpinan, budaya sekolah, motivasi terhadap kinerja guru SMP Swasta Sultan Agung maka dapat di tarik kesimpulan bahwa gaya kepemimpinan $\left(\mathrm{X}_{1}\right)$, budaya sekolah $\left(\mathrm{X}_{2}\right)$, dan motivasi $\left(\mathrm{X}_{3}\right)$ memiliki pengaruh yang positif terhadap kinerja guru (Y) pada SMP Swasta Sultan Agung Pematangsiantar. Hal ini dapat dilihat dari hasil pengujian regresi yang menunjukkan tanda positif pada persamaan sebagai berikut: $\mathrm{Y}=7,480+0,354 \cdot \mathrm{X}_{1}+0,269 \cdot \mathrm{X}_{2}+0,241 \cdot \mathrm{X}_{3}$. Berdasarkan hasil uji korelasi, menunjukkan bahwa gaya kepemimpinan, budaya sekolah, dan motivasi masing - masing memiliki korelasi yang sangat kuat dan signifikan terhadap kinerja guru SMP Swasta Sultan Agung Pematangsiantar. Secara parsial $(U j i-t)$, gaya kepemimpinan, budaya sekolah, dan motivasi berpengaruh signifikan terhadap kinerja guru SMP Swasta Sultan Agung Pematangsiantar. Berdasarkan pengaruh secara parsial yang terjadi antara variabel bebas (gaya kepemimpinan, budaya sekolah, dan motivasi) terhadap kinerja guru, dapat disimpulkan bahwa pengaruh yang paling dominan diantara ketiganya adalah variabel gaya kepemimpinan. Hasil presentase penilaian pengaruh kinerja guru SMP Swasta Sultan Agung Pematangsiantar yaitu sebesar $83,2 \%$ (uji determinasi, $\mathrm{R}^{2}=0,823$ ) dengan gaya kepemimpinan, budaya sekolah, dan motivasi, dan sisanya $(16,8 \%)$ dapat dijelaskan oleh faktor lain yang tidak dibahas dalam penelitian ini, seperti komitmen organisasi, kompetensi, kepuasan kerja, iklim organisasi, dan faktor lainnya. 


\section{DAFTAR PUSTAKA}

Adinata, U. W. S. (2015). Pengaruh kepemimpinan transformasional, motivasi dan budaya organisasi terhadap kinerja karyawan KJKS BMT Tamzis Bandung. Jurnal Ekonomi, Bisnis \& Enterpreurship, 9(2), 136-157.

Aguswara, W. W., \& Rachmadtullah, R. (2017). Pengaruh gaya kepemimpinan kepala sekolah dan iklim organisasi dengan kinerja guru Pendidikan Anak Usia Dini. Jurnal Pendidikan Usia Dini, 11(2), 369-387. doi:https://doi.org/10.21009/JPUD.112.14

Al Hadromi, F. (2017). Analisis pengaruh gaya kepemimpinan kepala sekolah terhadap motivasi, kedisplinan dan kinerja guru di SD Islam Lumajang. Jurnal Bisnis dan Manajemen, 11(1), 109-123.

Ardiana, T. E. (2017). Pengaruh motivasi kerja guru terhadap kinerja guru akuntansi SMK di Kota Madiun. Jurnal Akuntansi dan Pajak, 17(2), 14-23. Doi:http://dx.doi.org/10.29040/jap.v17i02.11

Eros, E. (2014). Pengaruh motivasi dan kedisiplinan kerja guru terhadap kinerja guru di SMP Negeri Kecamatan Brebes Kabupaten Brebes Jawa Tengah. Jurnal Adminitrasi Publik dan Birokrasi, 1(1), 1-12.

Greenberg, J. (2010). Managing In Organization (5th ed.). New Jersey: Pearson Education, Inc.

Hadi, S. (2015). Pengaruh gaya kepemimpinan terhadap kinerja guru dan pegawai tata usaha MTs Negeri Ngawi. Jurnal AL-MURABI, 1(2), 49-62.

Handayani, T., \& Rasyid, A. A. (2015). Pengaruh kepemimpinan kepala sekolah, motivasi guru dan budaya organisasi terhadap kinerja guru SMA Negeri Wonosobo. Jurnal Akuntabilitas Manajemen Pendidikan, 3(2). 265-277. doi:http://dx.doi.org/10.21831/amp.v3i2.6342

Hasibuan, M. S. (2005). Manajemen sumber daya manusia (edisi revisi). Jakarta: Bumi aksara.

Jumriatunnisah, N., \& Hasmin T. (2016). Pengaruh budaya sekolah, kompensasi dan motivasi internal terhadap kinerja guru honorer pada Sekolah Menengah Atas (SMA) di Kecamatan Madapangga Kabupaten Bima. Jurnal Mirai Management, 1(1), 25-41. doi:https://doi.org/10.1234/mirai.v1i1.3

Luthans, F. (2006). Perilaku organisasi (10th ed.). Yogyakarta: Andi.

Mangkunegara, A. A. P. (2008). Manajemen sumber daya manusia. Bandung: PT Remaja Rosdakarya.

Meindinyo, R. O., \& Ikurite, N. (2017). Influence of motivation on teachers perfomance in a local government area in Nigeria. Journal of Humanities and Social Science, 22(5), 22-28.

Mulyasa, E. (2003). Kurikulum Berbasis Kompetensi. Bandung: Remaja Rosdakarya.

Pramesti, D., \& Muhyadi, M. (2018). Faktor-faktor yang mempengaruhi kinerja guru SMA. Harmoni Sosial: Jurnal Pendidikan IPS, 5(1), 43-56. doi:https://doi.org/10.21831/hsjpi.v5i1.11854

Pramudyo, A. (2010). Analisis faktor-faktor yang mempengaruhi kinerja dosen negeri pada Kopertis Wilayah V Yogyakarta. Jurnal Bisnis dan Teori Implementasi, 1(1), 1-11.

Sidabutar, R. U. O., Lie, D., \& Inrawan, A. (2017). Pengaruh kepemimpinan kepala sekolah dan budaya sekolah terhadap kinerja guru pada SMP Negeri 1 Panei. Jurnal Manajemen dan Keuangan, 5(2), 38-46.

Suharto, B. C. (2005). pengaruh budaya organisasi, kepemimpinan dan motivasi kerja terhadap kinerja sumber daya manusia di Sekretariat DPRD propinsi Jawa Tengah. Jurnal Jurnal Riset dan Bisnis Indonesia, 1(1), 369-387.

Presiden Republik Indonesia. (2003). Undang-Undang Nomor 20 Pasal 3, tahun 2003 tentang Sistem Pendidikan Nasional. 
Wibowo, A., \& Ari, S. (2017). Kepemimpinan intrapreneurship, budaya sekolah dan kinerja inovasi guru. Jurnal Pendidikan Ekonomi dan Bisnis, 5(2), 176-193. doi:https://doi.org/10.21009/JPEB.005.2.5 